\title{
Near-Field Modular Antenna Concept with Configurable Reading Area for RFID Applications
}

\author{
Mossaab Daiki, Etienne Perret, Senior IEEE Member
}

\begin{abstract}
This paper presents a near-field antenna with significant reading area that is reconfigurable. This antenna is used to realize near-field UHF RIFD reader. The antenna is printed on a flexible plastic substrate and then cut to the desired dimensions to be positioned over the area where it is desired to carry out the reading of near-field UHF RFID tags. This new concept of configurable antenna on demand, which is cut to fix the reading zone, shows extremely modular characteristics and can be simply implanted in a real environment. The performances of different configurations of the antenna that tell about different reading surfaces are presented. Significant reading surfaces never obtained before for near-field UHF RFID tags $\left(1 \times 1 \mathrm{~cm}^{2}\right)$ up to $42 \times 76 \mathrm{~cm}^{2}$ with a minimum range of $15 \mathrm{~cm}$ for the $868 \mathrm{MHz}$ band are reported. Reading areas in three dimensions of such antennas are characterized experimentally with commercial tags to confirm the performances in a real environment.
\end{abstract}

Index Terms-Near-field antenna, magnetic field, meander dipoles, configurable, UHF RFID.

\section{INTRODUCTION}

$\mathrm{R}$ adio frequency identification technology in the UHF band (UHF RFID) is an extremely powerful approach to identify objects; thanks to its ability to perform multiple readings simultaneously, while providing a significant read range [1]-[9]. A passive UHF RFID system, in its simplest form, consists of a reader having an antenna and a transponder or tag, which is often completely passive and without any battery. The passive tag is powered by the remote interrogation signal from the reader [5], [6], [9], which is the major advantage of this communication system. The passive UHF RFID system's range is about $10 \mathrm{~m}$ with standard dimension tags (in the order of $10 \times 1 \mathrm{~cm}^{2}$ ) [4], [5], [8], [9] . These tag dimensions could be too large for some particular case of use, for example when the object to track is very small [7], [10][8] This is the reason why near-field UHF RFID systems have emerged. They represent an intermediate solution between UHF RFID and HF RFID. Indeed, such as in HF RFID inductive coupling for data exchange is used. However, the system is operating in the UHF frequency band.

M. DAIKI. is with Univ. Grenoble Alpes, LCIS, F-26900, Valence, France (e-mail: mossaab.daiki@lcis.grenoble-inp.fr).

E. PERRET. is with Univ. Grenoble Alpes, LCIS, F-26900, Valence, France (e-mail: etienne.perret@ lcis.grenoble-inp.fr) and Institut Universitaire de France, 75005, Paris, France
At this frequency $(860-960 \mathrm{MHz})$ tag dimensions can be much smaller, and the reading distance can increase [4], [5], [8], [9]. When compared with HF RFID, it is also a possibility to reduce the cost of tags. On the other hand, when compared with far-field UHF RFID, it is possible to keep good reading reliability. In addition, using the communication protocols of UHF RFID, systems have read rates higher than that in HF RFID; so, it will be possible to detect a lot of tags at the same time [10]. However, the reading area is drastically reduced when compared with the standard UHF RFID. Reading distances are limited (about $15-30 \mathrm{~cm}$, depending on the tag dimensions), which in some particular cases can provide a significant advantage by avoiding undesirable cross-reading phenomena. For these reasons, this approach is increasingly used for traceability applications such as item-level tagging or pharmaceutical management. It is also used for the control of the production systems where UHF RFID tags are used as sensors during all phases of production. In this case, near-field UHF RFID permits the use of several sensors that are attached to small-sized products [7], [10]. The items in these applications are characterized by their small sizes (much lower than the conventional UHF tag dimensions) and for some of them, by a lower cost than standard UHF tags. For example, a near-field UHF tag can have a total size of $1 \times 1 \mathrm{~cm}^{2}$, which makes its use compatible with a large number of applications such as jewelry. Near-field UHF RFID systems use inductivecoupling mechanism to exchange data. Therefore, reader antennas are designed to work in the Rayleigh zone [10]. Thus, the reading range is a function of the magnetic field amplitude variation produced by the reader antenna. Most of the UHF RFID tag antennas are based on a dipole or a loop topology. Some of them are composed of a single loop with two meander dipole branches [6], [8], [9]. So, even for a farfield UHF tag, the loop catches a part of the reader interrogation signal through magnetic field coupling. For nearfield tag, the radiative antenna part is unnecessary. This explains why near-field UHF tags can have very small dimensions when compared with classical UHF tags. For nearfield UHF RFID reader antenna, the most-used topology is the loop form, which is segmented to ensure the presence of a strong magnetic field, with a distribution as constant as possible inside the loop [11]-[17]. With this approach, it is 
possible to obtain a reading surface of the order of $20 \times$ $20 \mathrm{~cm}^{2}(0.58 \lambda \times 0.58 \lambda$ at $868 \mathrm{MHz}$, where $\lambda$ is the wavelength $)$ with a read range up to $30 \mathrm{~cm}$. Indeed, in near-field communication, the reading zone generally corresponds to the antenna surface. In that case, the length of the loop is comparable with the wavelength; more exactly, the loop circumference is about twice the wavelength at $868 \mathrm{MHz}$ [11], [13]-[15]. So, without any segmentation, the current distribution along the solid loop would null and change directions several times (every half wavelength), which would directly affect the magnitude and the uniformity of the magnetic field [11], [16], [17]. The segmentation technique ensures that the current along the loop keeps the same direction and therefore produces a constant magnetic field [11], [16], [17]. This design approach is characterized by the presence of a large number of small gaps of around $0.5 \mathrm{~mm}$. Therefore, a high number of mesh cells, a huge simulation time and resources are generally needed when three dimensions full wave simulation software such as CST Microwave MWS [18] are used. The designing time is high, especially when the diameter of the antenna is large. Indeed, the segmentation technique makes the structure resonant at a frequency that has to be matched with the operating frequency. When the dimensions of the loop are changing, the whole design part has to be simulated again.

To overcome some of these constraints, other topologies have been introduced for near-field UHF RFID reader antenna. To enlarge the reading zone is an important topic and improvements in this field are particularly awaited. In the literature, several structures have been introduced. One class uses the principle of standing wave [19]. The antenna described in [19], [12] has the form of a transmission line having a length of $1 \mathrm{~m}$ loaded with $50 \Omega$ impedance. To improve the distribution of the electric field, a meander shape is used. A maximum range of $30 \mathrm{~cm}$ using standard UHF RFID tags $\left(10 \times 1 \mathrm{~cm}^{2}\right)$ is obtained. Another antenna based on the same technique [20] is composed of a micro-strip line, which excites a set of slots to enhance the electric field in a specific space region. This antenna has a reading area of $40 \times$ $32 \mathrm{~cm}^{2}$ and a maximum range of $3 \mathrm{~cm}$ for tag sizes of $3 \times$ $3 \mathrm{~cm}^{2}$. A traveling wave antenna used for near-field UHF RFID application is proposed in [21]. The antenna is formed by two coplanar lines of $88 \mathrm{~cm}$ length and a reflector plane placed below at a distance of $2 \mathrm{~cm}$. The antenna produces a magnetic field located in a limited zone, just above the line. A read range of $5 \mathrm{~cm}$ over a surface of $240 \mathrm{~cm}^{2}$ is obtained with a button tag of $1.1 \mathrm{~cm}$ of diameter. Another design proposed in [22] is based on two meander coplanar lines and a reflector plane located $1 \mathrm{~cm}$ above the substrate. With UH113 tags [23], this antenna covers a reading area of $27.5 \times 13.5 \mathrm{~cm}^{2}$, which is equivalent to its surface. With a $1 \times 1 \mathrm{~cm}^{2}$ tag size, a reading zone about $74 \times 17 \times 3 \mathrm{~cm}^{3}$ is achieved by an antenna formed by adjacent microstrip lines [24].

In this paper, a modular near-field antenna is proposed. Contrary to the structures already introduced, the antenna is composed of different blocks, like parasitic elements, which act as resonators and are coupled electromagnetically with the driven element. Thanks to these blocks, the magnetic field repartition all around the antenna can be modified. Thus, the antenna shape is easily reconfigurable to obtain the desired reading zone, which can also be very important when compared with the state of the art. Moreover, this antenna has a low manufacturing cost; for instance, discrete elements are not needed. This antenna is made on PET substrate by lowcost processes, which are compatible with the realization of very large structures. The reading range of this antenna is significant and not really affected by any change of the blocks configuration.

In the first part, the conception method and the retained antenna configuration are presented. Then, simulation results in terms of magnetic field distribution and antenna bandwidth are discussed. The manufacturing process is described in the third section. Finally, antenna characterization results in a real environment are given.

\section{ANTENNA DESIGN}

\section{A. Antenna description}

The proposed antenna is composed of different blocks; each having dimensions of $12 \times 16 \mathrm{~cm}^{2}$. These blocks can be printed on a flexible plastic substrate, and the final antenna is composed of an arrangement of these blocks to achieve the expected reading surface. The possibility of changing the block positions gives a modular character that can be useful for practical applications. Fig. 1 shows the two different types of blocks that are used for the conception of the entire antenna: one corresponds to the driven element and the other acts like parasitic elements.

Each block contains 11 meandering lines. In each block, the meander lines are organized as follows: 10 identical meander lines are set vertically along the $y$-axis (Fig. 1). The $11^{\text {th }}$ meander line, which is identical to the others, is placed horizontally along the $x$-axis as shown in Fig. 1(a). The second block, the excitation block, is shown in Fig. 1(b). When compared with the first block, it contains an additional dipole connected to a $50 \Omega$ SMA (sub miniature version A) coaxial connector.

For printed dipole, the resonance frequency $f$ is controlled by the dipole length $l$ as shown in (1) - (2) [25].

$$
\begin{aligned}
& \lambda=\frac{c}{f \sqrt{\varepsilon_{\text {eff }}}} \\
& l=\frac{\lambda}{2}
\end{aligned}
$$

where $c$ is the velocity of light and $\varepsilon_{\text {eff }}$ the effective permittivity. In the case of a relatively thick substrate $(d>\lambda / 10)$, the effective permittivity can be considered to be 
equivalent to the average of the free space and the substrate dielectric permittivity $\varepsilon_{r}$.

$$
\varepsilon_{\text {eff }}=\frac{\varepsilon_{r}+1}{2}
$$

Here, the antenna is printed on a PET substrate $\left(\varepsilon_{r}=3\right)$ with a very low thickness $(d=100 \mu \mathrm{m})$. So, when the printed dipole is in free space, the substrate will not influence the resonance frequency $\left(\varepsilon_{e f f}=\varepsilon_{0}\right)$. However, for real applications, the printed dipole can be put down on a table for example, and the effective permittivity has to be calculated with (3). Both cases will be considered in the following. For instance, in free space, using (1)-(3), a length equal to $l=17.2 \mathrm{~cm}$ at $868 \mathrm{MHz}$ is first obtained. This value is very close to the one found after an optimization process based on CST, where a slightly greater length is obtained: $18 \mathrm{~cm}$ for excitation dipole and $17.8 \mathrm{~cm}$ for other meandered lines (see Fig. 1). Meander lines parameters have been chosen after an optimization realized on CST. The objective was to choose the dipole excitation dimensions to match the $50 \Omega$ input impedance (SMA connector) at the desired frequency. The same dimensions have been kept for the passives meander lines.

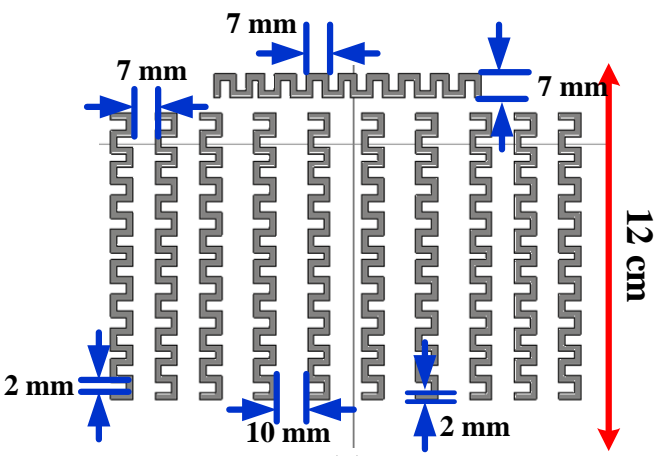

(a)

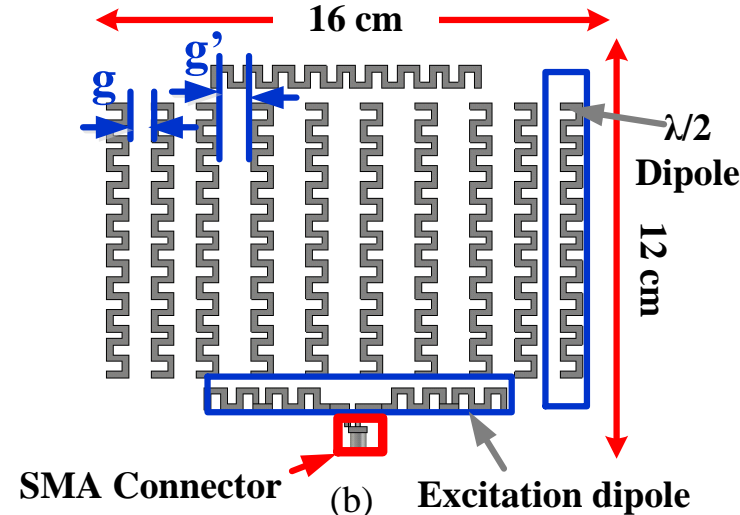

Fig. 1. Topology of the blocks composing the antenna: (a) peripheral block, (b) block containing the driven element.

For both types of blocks, the distance between meander lines is about $1 \mathrm{~cm}$. Thus, an important coupling is created between the different lines. As we will see, all the meandered lines will contribute to generate a strong magnetic field around the structure. The important aspect is that a large number of different antenna topologies can be obtained just by choosing the total number of blocks and their spatial arrangement.

Thanks to this original concept, the desired reading zone can be easily obtained due to the modular character of these

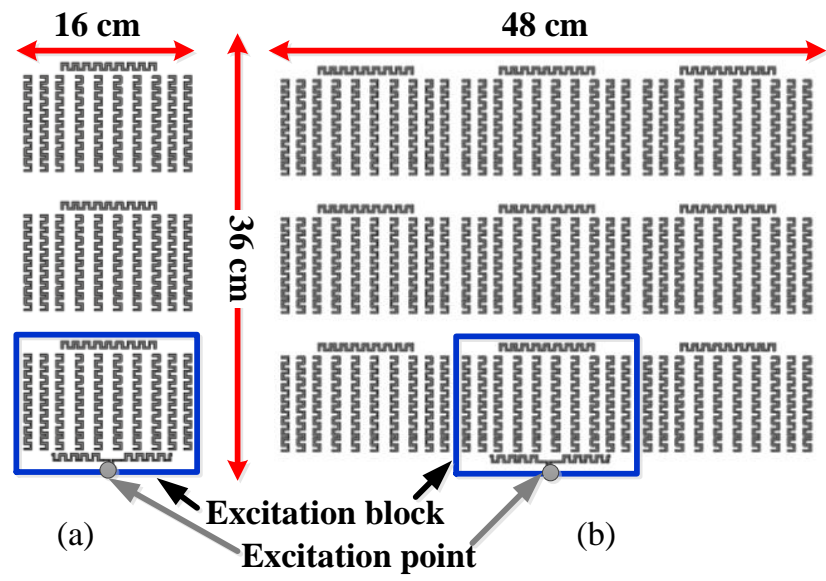

Fig. 2: Near-field RFID antenna designs: (a) configuration with 3 blocks, (b) configuration with 9 blocks.

blocks. At least, only one excitation block [Fig. 1(b)] is needed, the other blocks are used to reach the reading surface expected for the application. Lots of configurations are possible; for example, Fig. 2 shows a configuration with 3 and 9 blocks. Thanks to the dipoles arrangement inside a block and the blocks arrangement, a significant and uniform magnetic field distribution can be obtained over the entire surface covered by the blocks. This is possible because the additional parasitic blocks surrounding the driven element do not affect the frequency response of the antenna much. We will see that the operating frequency is controlled by the excitation block whatever be the block configuration used. Note that parasitic elements are classically used for far-field antenna design [26], but not for near-field considerations.

\section{B. Antenna design}

\section{1) Study of the parasitic elements shape}

The parasitic elements play a key role in the antenna design. These conductive elements, which are not electrically connected to the feed, are used as a passive radiator to homogeneously allocate the magnetic field all around the antenna (and not for far-field considerations). In this particular case, the purpose of the parasitic elements is to modify the near-field pattern emitted by the driven element. By carefully designing these passive elements, it is possible to control the distribution of the magnetic field, and so the reading volume of the antenna. In our case, the parasitic elements are short-

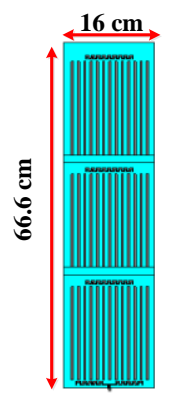

(a)

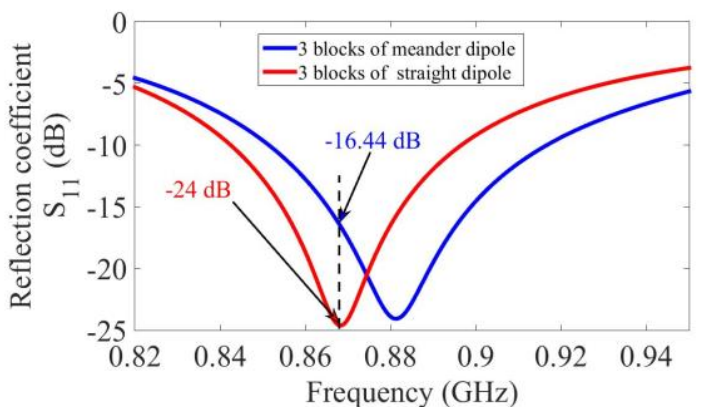

(b)
Fig. 3 (a) Straight short-circuited dipoles, 3 blocks configuration, (b) return loss of the corresponding near-field antenna and the meander dipole (Fig. 1) configuration. 
circuited dipoles that act like passive resonators, accumulating a part of the electromagnetic field from the nearby driven element to control its distribution and then to improve nearfield RFID reading. The effect of the passive element shape on the magnetic near-field is investigated through the study of two different shapes: the meander lines (see Fig. 1) and the classical straight line presented in Fig. 3(a).

The excitation dipole remains exactly the same (meander shape). A comparison between these two shapes for the 3 blocks configuration is given in Fig. 4. For the straight line configuration, two different horizontal parasitic elements have been simulated: a meander and a straight line similar to the vertical elements. The best result, obtained with a meander line has been chosen to be plotted in Fig. 4. The input power considered is always $1 \mathrm{~W}$. We can note in Fig. 3(b) that both antennas are well matched to the operating frequency band. It is clear from Fig. 4 that the meander lines allow one to obtain better homogenization of the magnetic field amplitude on the antenna surface. A read range of $20 \mathrm{~cm}$ and a reading surface at $3 \mathrm{~cm}$ of $288 \mathrm{~cm}^{2}$ is obtained with the straight lines configuration. If we compare these results with the meander line configuration (with the same number of blocks: 3 ), it is $9 \mathrm{~cm}$ and $50 \%$ less for the read range and the reading surface respectively.

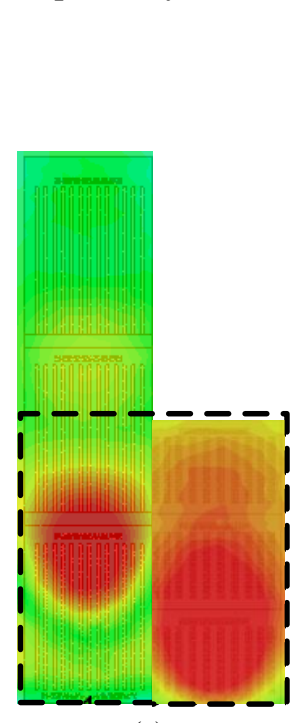

(a)

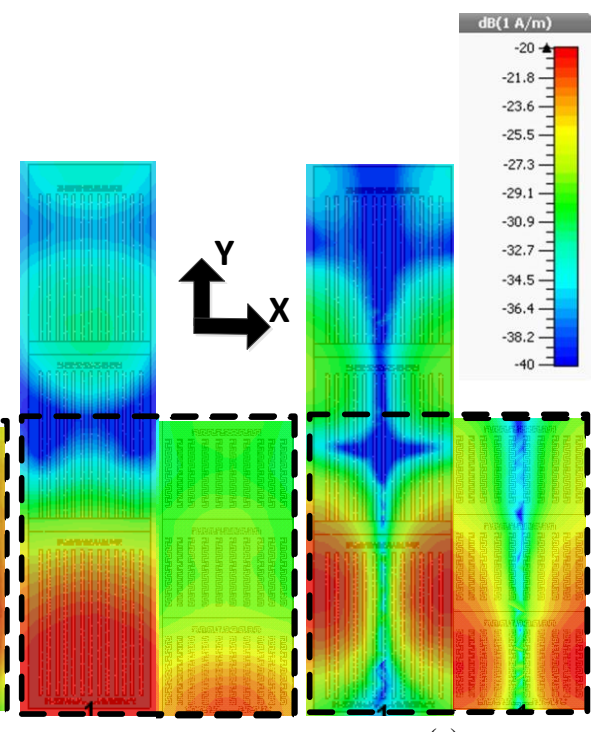

(b)

(c)
Fig. 4: Simulation of the magnetic field distribution (in $\mathrm{dBA} / \mathrm{m}$ ) for the 3 blocks configuration: comparison between the straight (left) and the meander (right) lines at $z=10 \mathrm{~cm}$ in the $(x, y)$ plane at $868 \mathrm{MHz}$ : (a) $z$ - component (Hz), (b) $y$-component $(H y)$, (c) $x$-component $(H x)$.

Contrary to the straight shape, the meanders create currents in different directions (along the $x$ - and $y$-axis), which produce better uniformity. This result shows the positive contribution of using a meander shape in the homogenization of the magnetic field. Thanks to this, on the entire surface defined by the passive elements, the reading will be less sensitive to the tag orientation. For the following, particular attention will be paid to the $\mathrm{Hz}$ component mainly for two reasons. 1) In a lot of applications, tags can be arranged in such a manner that the loop belongs to the $x, y$ plane and 2) as explained in the introduction, most of the reader antennas are based on a loop design; so, the normal component $\mathrm{Hz}$ is by far the most important one. That is why it is important to consider this component, and in Fig. 4(a) we clearly see that the magnitude of $\mathrm{Hz}$ is higher in the case of the meander lines. For the rest of the paper, the meander dipoles will be considered, and comparisons will be made using the normal component $\mathrm{Hz}$.

\section{2) Passive elements arrangement}

The spacing between the meander dipoles has been optimized to maintain a good matching in the $868 \mathrm{MHz}$ band and a large reading surface. Fig. 5 presents the effect of the reflection coefficient for different spacing between the meander lines for the 3 and 9 blocks configuration.

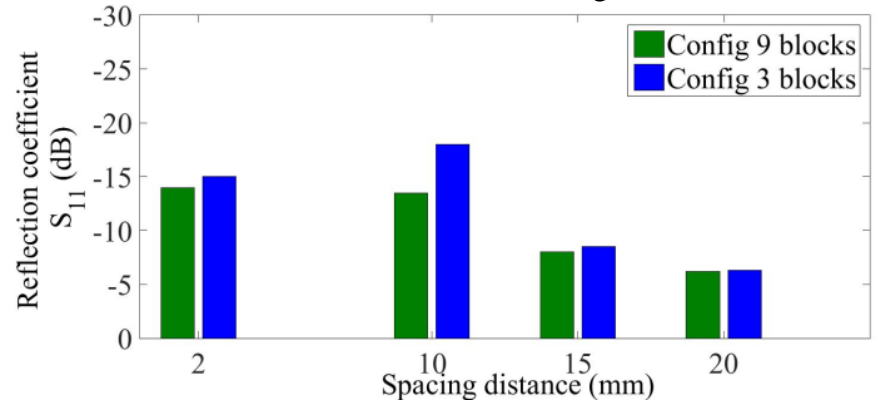

Fig. 5: Effect of the spacing distance $g=g$ ' (Fig. 1) on the antenna reflection coefficient for the 3 and 9 blocks configuration of the meander dipoles at $868 \mathrm{MHz}$

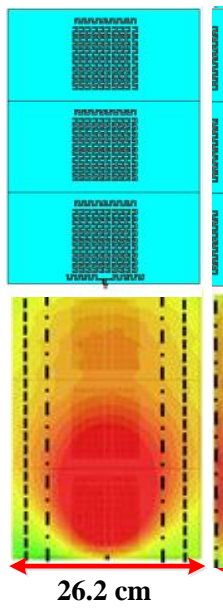

(a)

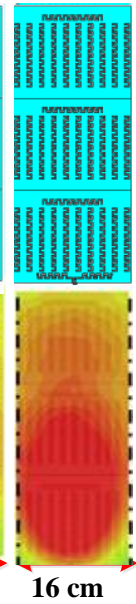

(b)

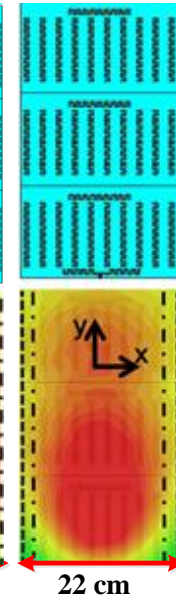

(c)

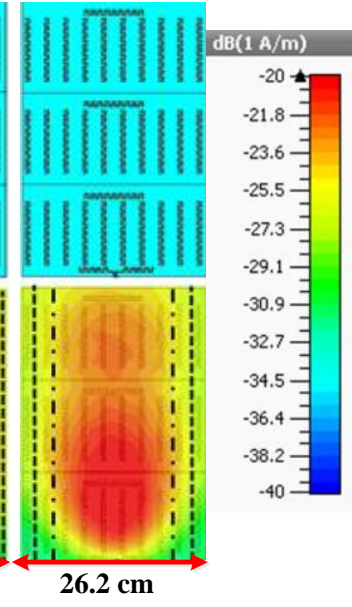

(d)
Fig. 6: Effect of the spacing distance $g=g^{\prime}$ (Fig. 1) on the magnetic field distribution $\mathrm{Hz}$ for the 3 blocks antenna configuration, $868 \mathrm{MHz}, z=10 \mathrm{~cm}$ : (a) $g=0.2 \mathrm{~cm}$, (b) $g=1 \mathrm{~cm}$, (c) $g=1.5 \mathrm{~cm}$, (d) $g=2 \mathrm{~cm}$.

We note that if we increase the spacing $g$ too much, the antenna matching can be degraded. Figs. 6 and 7 show that the spacing between the meandered lines has an impact on the magnetic field distribution. We notice that when we increase the gap $g$ too much, the $z$-component of the magnetic field decreases in both the $x$ - and $y$-direction. The spacing $g$ and $g$ ' has to be chosen in order to maintain both a good matching whatever be the configuration chosen and an important magnetic field on the surface defined by the presence of the passive elements. $g=1 \mathrm{~cm}$ represents a good compromise. However, a further optimization step has led us to consider two different spacing $g=1 \mathrm{~cm}$ and $g^{\prime}=0.7 \mathrm{~cm}$ as shown in Fig. 1. 


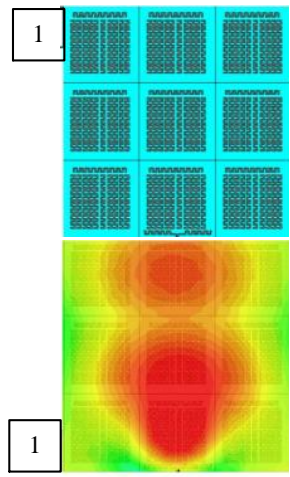

(a)

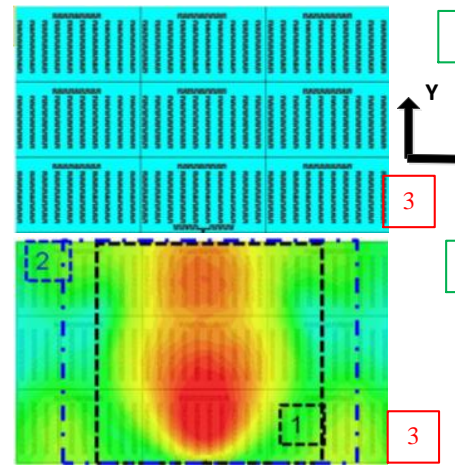

(c)

Fig. 7 Effect of spacing distance $g$ on the magnetic field distribution $\mathrm{Hz}$ for the 9 blocks antenna configuration at $868 \mathrm{MHz}$ and at $z$-plane $=10 \mathrm{~cm}$ : (a) $g=0.2 \mathrm{~m}$, (b) $g=1 \mathrm{~cm}$, (c) $g=1.5 \mathrm{~m}$, (d) $g=2 \mathrm{~m}$.

3) Magnetic field homogenization, the horizontal meandered line

The horizontal meandered line added above the vertical lines also plays an important role in the control of the magnetic field in the $y$-axis direction as we can see in Fig. 8.

The presence of this line also improves the matching of the antenna at the desired frequency. Final antenna dimensions are given in Fig. 1.

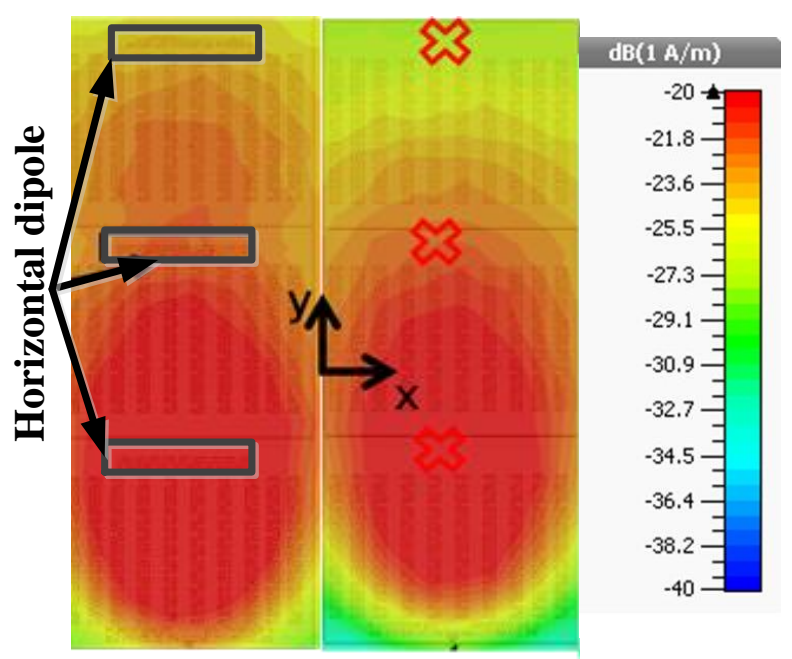

(a)

(b)

Fig. 8: Effect of the horizontal dipole on the magnetic field distribution $\mathrm{Hz}$, $868 \mathrm{MHz}, z=10 \mathrm{~cm}$, for the 3 blocks antenna configuration: (a) with and (b) without horizontal meandered line.
To show the modular character of this antenna, several configurations have been studied in simulation and measurement. In the next section, we will focus on four specific configurations: a single block $(12 \times 16 \mathrm{~cm}), 3$ blocks $(36 \times 16 \mathrm{~cm}), 9$ blocks $(36 \times 48 \mathrm{~cm})$ and 15 blocks $(36 \times$ $80 \mathrm{~cm})$. The different antenna configurations are shown in Table I. All the configurations are simulated with CST Microwave. As shown in Fig. 1(a), the SMA connector is always simulated with the antenna to take into account the unbalanced behavior of the excitation.

\section{SimUlation RESUltS}

Different antenna configurations are simulated to study the impact of the repartition and the number of blocks. Table I shows the reflection coefficient $\left(S_{11}\right)$ at $868 \mathrm{MHz}$ of the different antenna configurations. We note that the antenna is well matched whatever the configuration be considered. The total magnetic field distribution for configurations with 1, 3, 9, and 15 blocks at $z=1 \mathrm{~cm}$ is shown in Fig. 9. We observe that the antenna presents an important magnetic field on its entire surface, whatever be the configuration. Because of the input power used in simulation ( $1 \mathrm{~W}$ ) and the nature and the sensibility of the near-field RFID tag that we considered in the measurement part (AK tag [27]), $-20 \mathrm{dBm}$ [16] can be considered as the minimum magnetic field magnitude that is needed to awaken the tag.

\begin{tabular}{|c|c|c|c|}
\hline $\begin{array}{l}\text { ANTENNA } \\
\text { CONFIGURA- } \\
\text { TION }\end{array}$ & $\begin{array}{l}\text { ANTENNA PICTURE } \\
(\text { (CM X CM })\end{array}$ & $\begin{array}{c}\mathrm{S}_{I I}(\mathrm{~dB}) \\
868 \mathrm{MHz}\end{array}$ & $\begin{array}{c}\text { GAIN } \\
\text { (LINEAR) } \\
868 \mathrm{MHZ}\end{array}$ \\
\hline \multirow[t]{2}{*}{1 block } & 16 & & \\
\hline & 12 & -15.4 & 1.43 \\
\hline \multirow[t]{2}{*}{3 blocks } & 10 & & \\
\hline & 36 & -18 & 1.68 \\
\hline
\end{tabular}

9 blocks

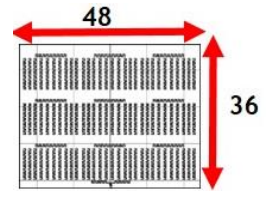

$-13.8$

15 blocks

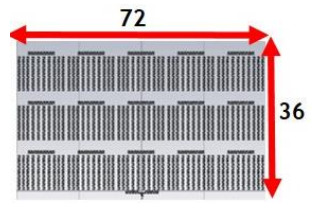




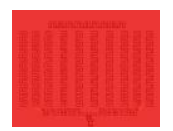

(a)
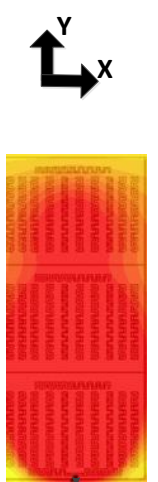

(b)

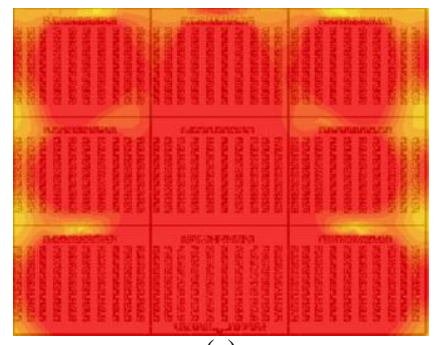

(c)

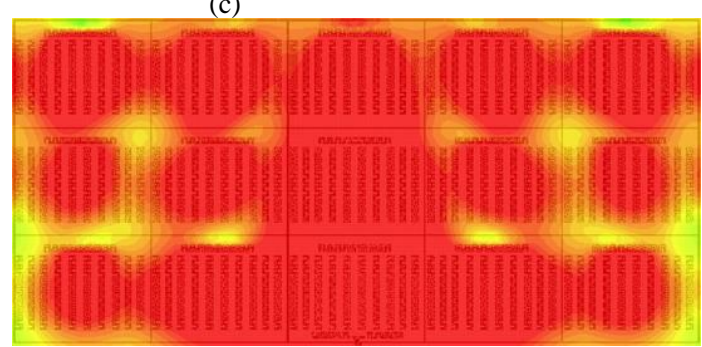

(d)

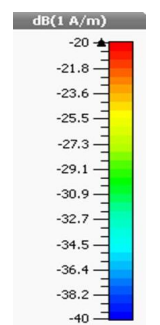

Fig. 9: Simulated normal magnetic field magnitude $\mathrm{Hz}$ at $z=1 \mathrm{~cm}, 868 \mathrm{MHz}$ for 3 different configurations: (a) 1, (b) 3, (c) 9, and (d) 15 blocks.

If we consider this assumption, we can see that a small tag $\left(1.1 \times 1.2 \mathrm{~cm}^{2}\right)$ can be read on a very large surface depending on the block repartition used.

In practice, a reflector plane is usually added below a nearfield antenna at a distance of $4 \mathrm{~cm}$ to enhance the distribution of the magnetic field on the top of the antenna and to prevent tags reading below the antenna plane [21], [28].

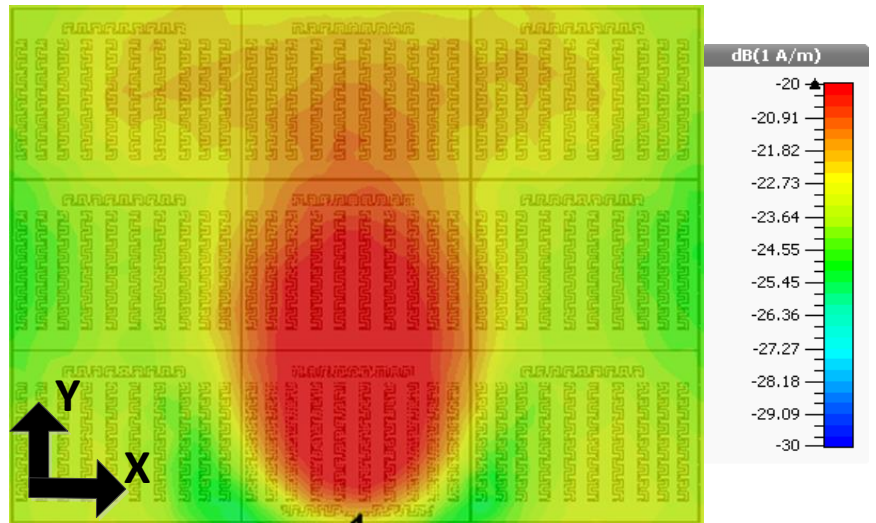

(a)
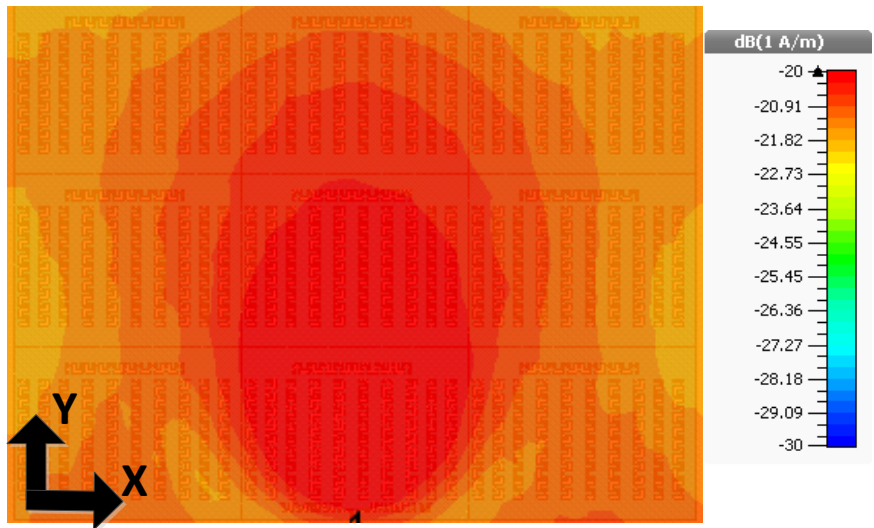

(b)

Fig. 10: Metallic plane effect for the 9 blocks configuration on the magnetic field distribution $\mathrm{Hz}$ at $868 \mathrm{MHz}, z=10 \mathrm{~cm}$ : (a) without, and (b) with a ground plane of dimensions $100 \times 50 \mathrm{~cm}^{2}$.
This effect is observed in Fig. 10 where a comparison of the total field magnitude obtained with and without a reflector plane is shown. With the ground plane, the magnetic field is more uniform and significant over the entire surface of the antenna.

\section{ANTENNA REALIZATION AND CHARACTERIZATION}

\section{A. Antenna realization}

The antenna blocks are printed at one time, side by side on a PET substrate [see Fig. 11(a)] using a copper printing realization technique compatible with low-cost realizations and large surfaces printing (200 $\times 28 \mathrm{~cm}^{2}$ in our case) [29], [30].

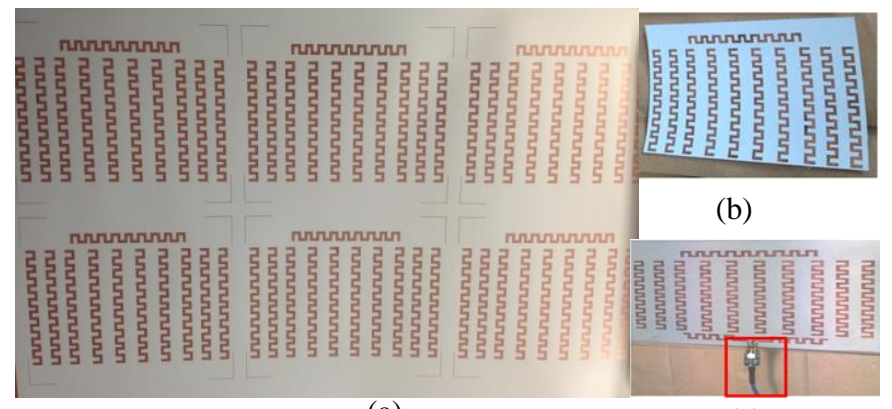

(a)

(c)

Fig. 11: Antenna realization: (a) printed passive element blocks before cutting, (b) peripheral block after cutting, (c) excitation block soldered to an SMA connector.

To demonstrate the modular character of the antenna, the blocks of dimensions $12 \times 16 \mathrm{~cm}^{2}$ are cut as shown in Fig. 11 . For the excitation block, the SMA connector is soldered to the dipole [see Fig. 11(c)]. Then, as shown in Fig. 12, the blocks are taped to a polyester substrate of $4 \mathrm{~cm}$ thickness, which plays the role of a support with a permittivity near to 1 . The different antenna confirmations are obtained by changing the blocks arrangement.

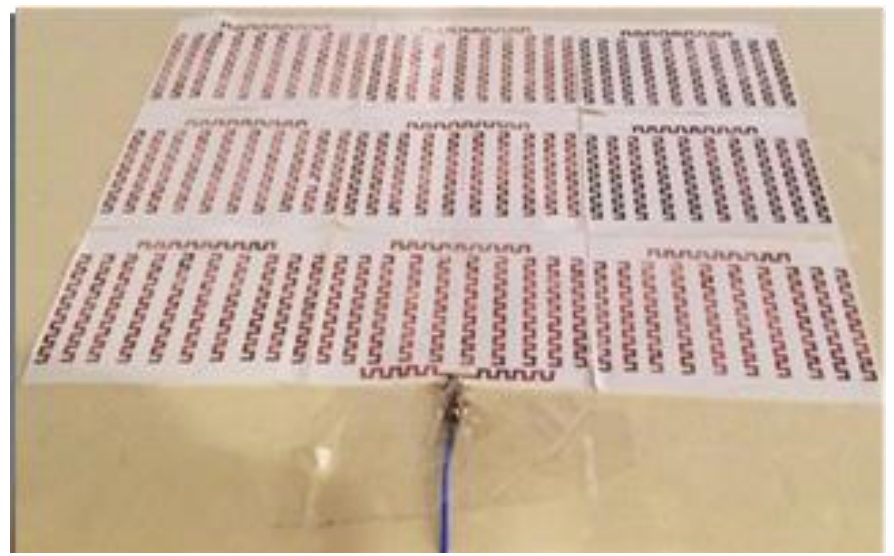

Fig. 12: Antenna prototype: the 9 blocks configuration. The PET printed blocks are taped on a polystyrene substrate.

\section{B. S-parameter measurement}

The reflection coefficient $S_{11}$ is measured for the different antenna configurations (1, 9, 15 blocks) with a network analyzer. The results are shown in Fig. 13. A good agreement between simulation and measurement results is obtained. As shown in Table 1, the reflection coefficient value around 
$868 \mathrm{MHz}$ is slightly influenced by the number of blocks. This explains why it is possible to easily modify the reading zone. For example, the 9 blocks antenna configuration has a bandwidth at $-10 \mathrm{~dB}$ of $70 \mathrm{MHz}(856-926 \mathrm{MHz})$, which covers the all UHF RFID frequency bands.

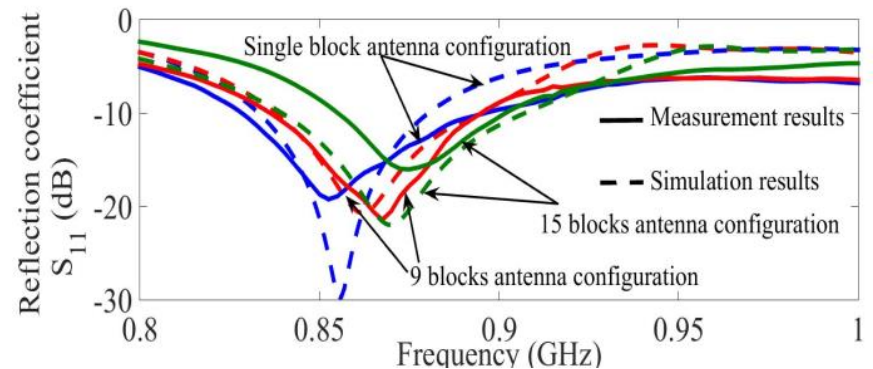

Fig. 13 Simulation and measurement results of the reflection coefficient for the 1,9 and 15 blocks antenna configuration.

\section{Reading performances}

The maximum range and reading area of the modular nearfield antenna is thus characterized. To do this, we use a 3D positioning table, a commercial UHF RFID reader [31], and a near-field tag [27]. The measurement setup is shown in Fig. 14(a). The AK tag is composed of a small loop with total dimensions equal to $1.2 \times 1.1 \mathrm{~cm}^{2}$ [see Fig. 14(b)]. The tag is placed on a movable support controlled by the $3 \mathrm{D}$ positioning system.
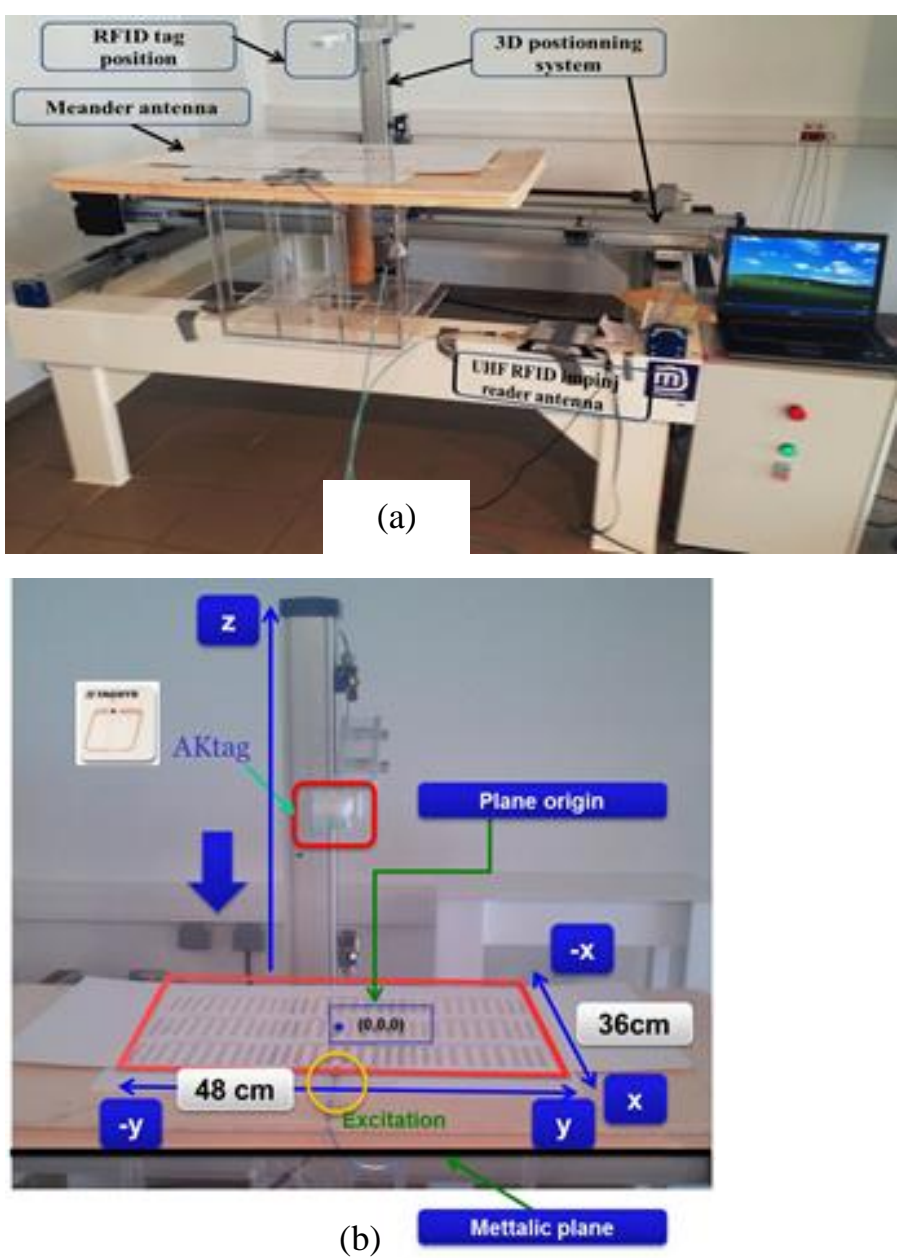

Fig. 14: (a) RFID measurement setup used to characterize the 3D reading zone of the near-field antenna, (b) characterization process.
As shown in Fig. 14(b), the antenna under test is fixed and by changing the tag position, it is possible to scan the total antenna surface ( $x, y$ plane). The 3D positioning table and the reader are automatically controlled through a program developed in MATLAB. The tag can move in a volume of 100 $\times 100 \times 35 \mathrm{~cm}^{3}$ [see Fig. 14(b)]. For each position $\left(x_{i}, y_{i}\right)$ of the tag, the reader detects if the tag is activated or not (detection of the tag ID). More precisely, the tag is initially set to the maximum height $(z=35 \mathrm{~cm})$, then it moves towards the antenna. For each position $\left(x_{i}, y_{i}\right)$, the maximum read range $z_{\max }$ is determined. In this way, the total $3 \mathrm{D}$ reading zone can be characterized.

\section{1) Reflector plane effect}

The 9 blocks antenna configuration presented in Fig. 12 is characterized using the cartography setup described previously. An RFID reader output power of $30 \mathrm{dBm}$ is used. The results are shown in Fig. 15(a). A reading range greater than $10 \mathrm{~cm}$ for the whole scanned surface of the antenna $(48 \mathrm{x}$ $36 \mathrm{~cm}^{2}$ for 9 blocks configuration) is obtained.

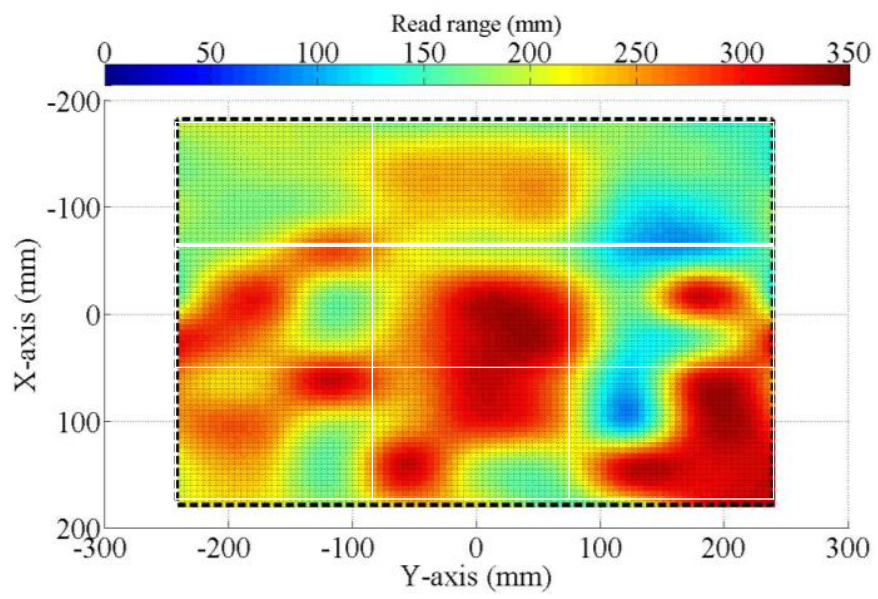

(a)

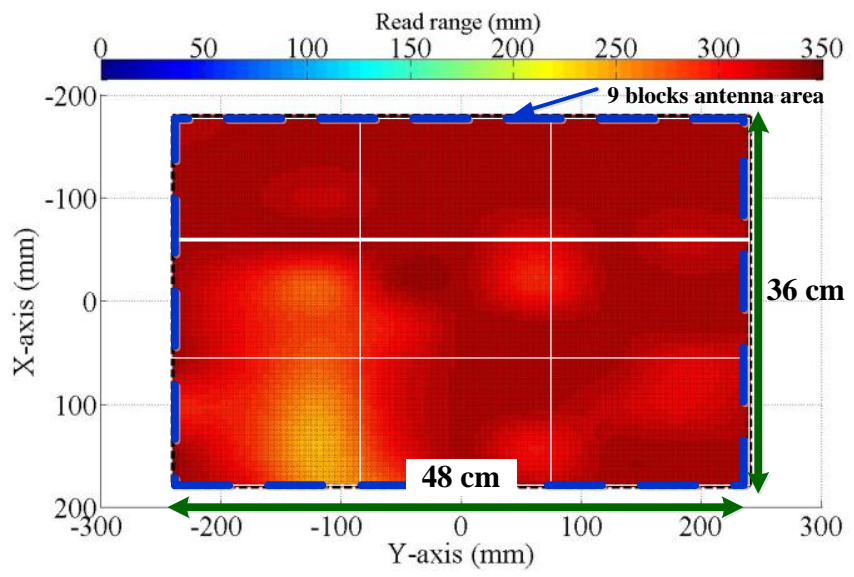

(b)

Fig. 15: Measurement results of the reading zone of the 9 blocks meandered antenna configuration: (a) without and (b) with a metallic plan below the antenna $\left(100 \times 50 \mathrm{~cm}^{2}\right)$. The reader output power level is $30 \mathrm{dBm}$. The lines (in white) delimit the different blocks.

For some specific regions (approximately a zone of $10 \times 15$ $\mathrm{cm}^{2}$ ), a reading range higher than $30 \mathrm{~cm}$ is reached. After that, a reflector plane $\left(50 \times 100 \mathrm{~cm}^{2}\right)$ is set $4 \mathrm{~cm}(\approx \lambda / 8)$ below the 
antenna [see Fig. 14(b)]. In Fig. 15(b), we can see that the read range is higher than $25 \mathrm{~cm}$ on the whole surface of the antenna $(48 \times 36 \mathrm{~cm})$.We note significant regions where the reading distance is higher than $35 \mathrm{~cm}$ (it is the limit of the 3D positioning system). The reflector plane provides more uniformity for the reading zone, and above all a huge read range. For the following part of the study, the reflector plane is used.

\section{2) Different reader power level measurement}

To study the reader output power effect on the reading zone, the 9 blocks configurations have been scanned for two different power levels 30 and $27 \mathrm{dBm}$. Fig. 16 shows the results for a power of $27 \mathrm{dBm}$ and the reduction of the read range is clearly observable when compared with Fig. 15(b). However, with a power of $27 \mathrm{dBm}$, the tag is still read over the entire surface $\left(48 \times 36 \mathrm{~cm}^{2}\right)$.

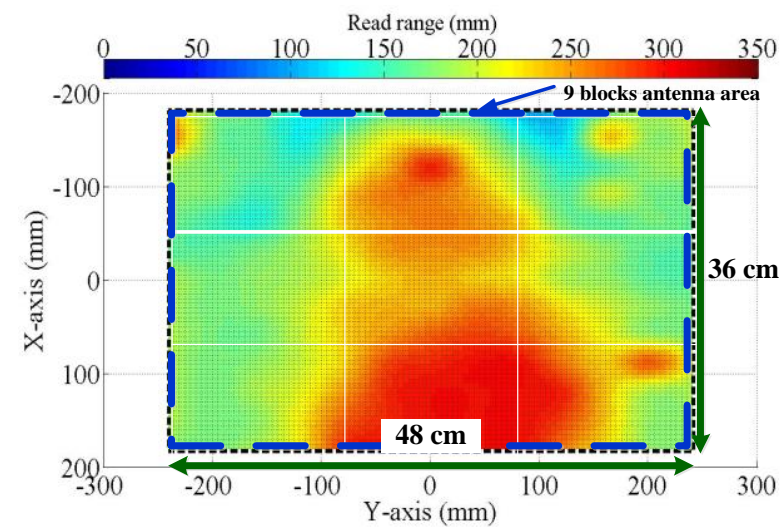

Fig. 16: Measurement results of the reading zone for a reader output power level of $27 \mathrm{dBm}$ for 9 blocks.

For the 15 blocks configuration, as we can see in Fig. 17, with an output power of $30 \mathrm{dBm}$, a reading surface of $76 \times$ $42 \mathrm{~cm}^{2}$ is obtained with a minimum range of $15 \mathrm{~cm}$. The simulated realized gain of this antenna is $3.89 \mathrm{~dB}$. The regulation for the European zone fixes the maximum effective radiated power to $2 \mathrm{~W}$. So, the reader power can be adjusted up to $29 \mathrm{dBm}(795 \mathrm{~mW})$ to respect the power regulation in Europe. Note that the large bandwidth of the antenna allows its use in US with a power level of $30 \mathrm{dBm}$.

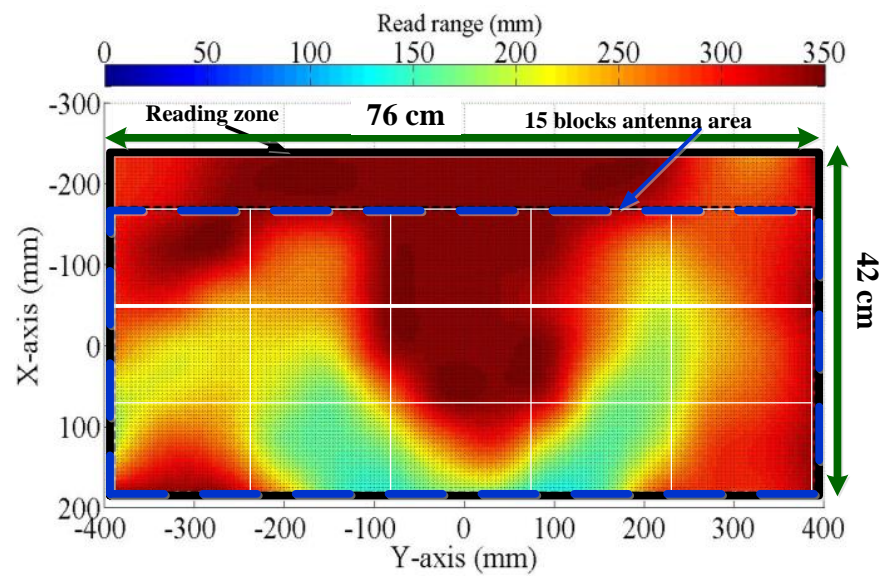

Fig. 17: Measurement results of the reading zone for the 15 blocks configuration with a reader output power level of $30 \mathrm{dBm}$.

\section{3) Effects on the blocks arrangement - antenna modular character}

In the objective to evaluate the influence of the blocks arrangement on the reading zone, the number of blocks used to form the antenna is varied around the central excitation module. Note that the whole results presented in this paper are obtained with the same panel of blocks. For example, the same excitation block has been used to realize all the different configurations presented.

For one configuration to another, only the number and the arrangement of the blocks are changing and not the geometry of the blocks. Considering the limit in the $z$-direction of the $3 \mathrm{D}$ positioning table, a reader output power level of $27 \mathrm{dBm}$ is used. The excitation block surface (1 block configuration) has been scanned with a reader output power level of $27 \mathrm{dBm}$. The results presented in Fig. 18(a) show that the minimum read range on the entire surface is around $18 \mathrm{~cm}$. A first comparison is carried out with the 3 and 9 blocks antenna configuration. The near-field UHF RFID tag scans the same surface $\left(48 \times 36 \mathrm{~cm}^{2}\right)$ for both configurations. The results are shown in Figs. 16 and 18 (b).

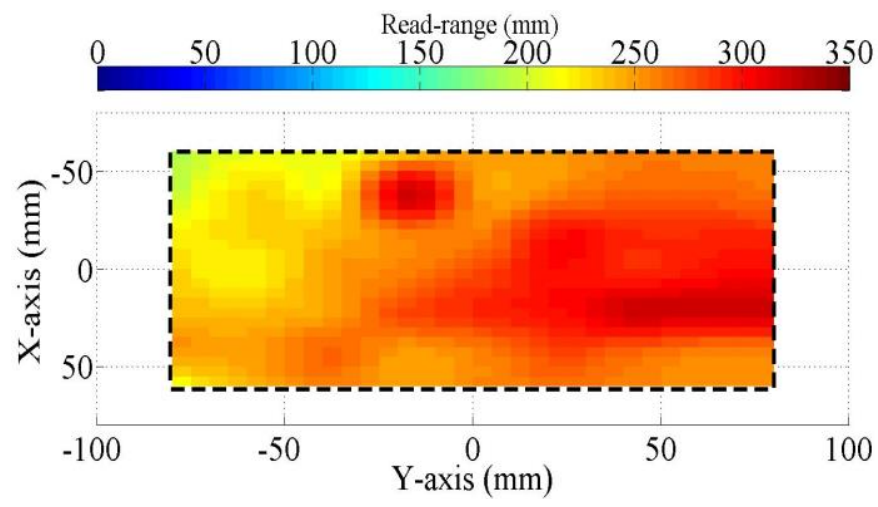

(a)

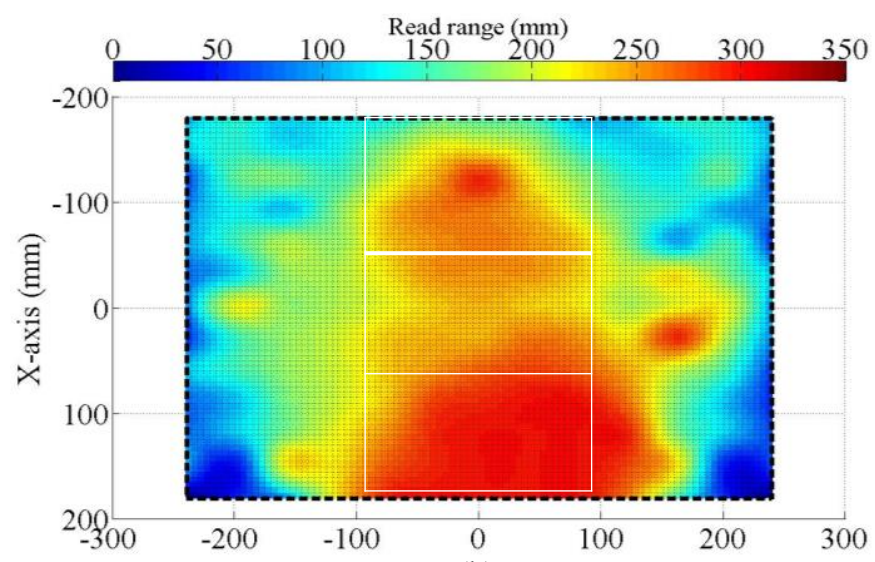

(b)

Fig. 18: Measurement results of the reading zone with a reader output power level of $27 \mathrm{dBm}$ : (a) for a single block, (b) for the 3 blocks

It can be seen that by increasing the number of blocks from 3 to 9 , it is possible to enhance the reading distance around the driven block. Note that the minimum reading range is $5 \mathrm{~cm}$ (respectively $12 \mathrm{~cm}$ ) for the 3 (respectively 9) blocks configuration. The maximum is obtained for the single block configuration with a read range of $18 \mathrm{~cm}$. Thus, where the blocks have been added, it is possible to read the tag. From 3 
to 9 blocks, the reading zone is enlarged to obtain $36 \times 48 \mathrm{~cm}^{2}$ with an improvement on the minimum reading range that is increased up to $15 \mathrm{~cm}$ for the 9 blocks configuration with a power of $27 \mathrm{dBm}$. Similarly, a surface of $42 \times 76 \mathrm{~cm}^{2}$ has been scanned for the 10 blocks configuration, with an output power of $30 \mathrm{dBm}$ (see Fig. 19).

We observe that the reading zone is slightly translated in the opposite direction of the excitation point. We also note that the reading zone exceeds the antenna surface. On the other hand, for the 15 blocks configuration at the same power level (Fig. 17), a reading area of $42 \times 76 \mathrm{~cm}^{2}$ is characterized. Both the 10 and 15 blocks configurations have a reading surface enlarged by $6 \times 76 \mathrm{~cm}^{2}$. We obtain the same maximum range of at least $35 \mathrm{~cm}$. The minimum range is about $8 \mathrm{~cm}$ for the 10 blocks configuration. It is lower than the 15 blocks one (15 $\mathrm{cm})$.

Because of the 3D positioning table limitations, it is not possible to characterize an arrangement of more than 15 blocks. In a power level of $30 \mathrm{dBm}$, we can see from Fig. 17 that the antenna has an important reading zone.

To go further, in Fig. 20, we present the reading zone for

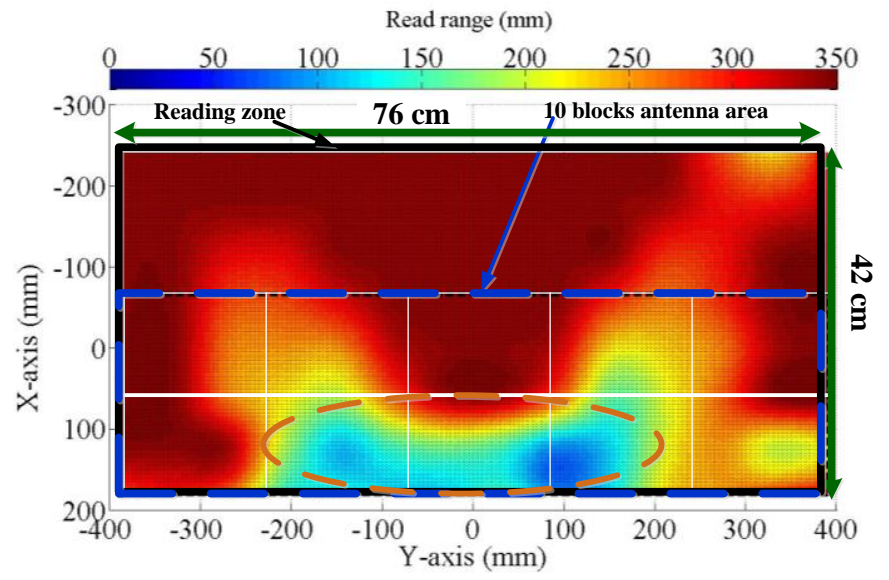

Fig. 19 Measurement results of the reading zone for the 10 blocks configuration for a reader power level of $30 \mathrm{dBm}$.

different configurations $(9,10,15$ blocks) and different heights cut $(z=[10,20,30] \mathrm{cm})$ and for a reader output power level of $30 \mathrm{dBm}$. Red color defines the reading zone at each height. With the 9 blocks configuration, we notice that the reading zone reaches more than $95 \%$ of the surface antenna regardless of the height from 10 to $30 \mathrm{~cm}$. A reading zone of about $80 \%$ is obtained at $30 \mathrm{~cm}$ for the 10 and 15 blocks configurations [Figs. 20(b) and (c)].

In summary, the larger near-field antenna characterized (that is to say the 15 blocks configuration) achieves a reading range higher than $35 \mathrm{~cm}$ on $60 \%$ of its $76 \times 42 \mathrm{~cm}^{2}$ surface. Outside this area, a range of $15 \mathrm{~cm}$ is obtained (Fig. 17). Thus, it is clear in Figs. 15-19 that the reading area can be controlled by changing the number of blocks.

The reading zone is flexible, and it is directly linked to the arrangement of the different blocks. The magnetic field distribution above the antenna is strongly related to the number of blocks and their positions relative to the driven block. Note that without the ground plane, the antenna can be integrated on many supports just by adjusting the excitation dipole length according to the support characteristic and (1)-
(3). By this way it is possible to compensate any frequency shift that can be observed in such configuration. It is also possible to maintain a similar magnetic field distribution, i.e. a constant read range.

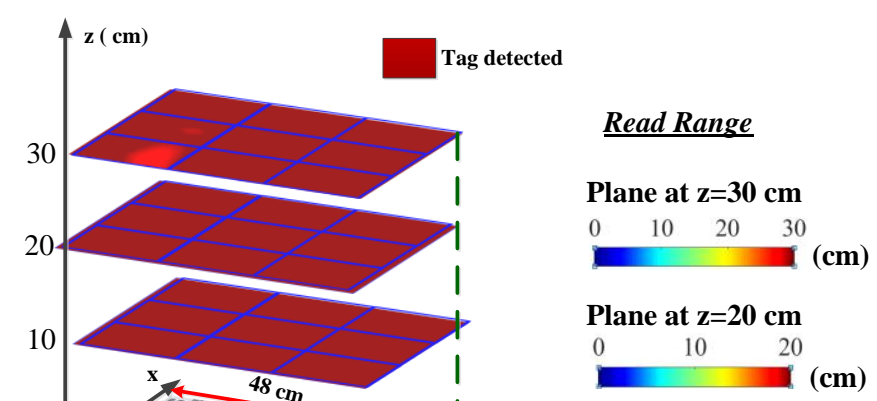

Plane at $\mathrm{z}=10 \mathrm{~cm}$
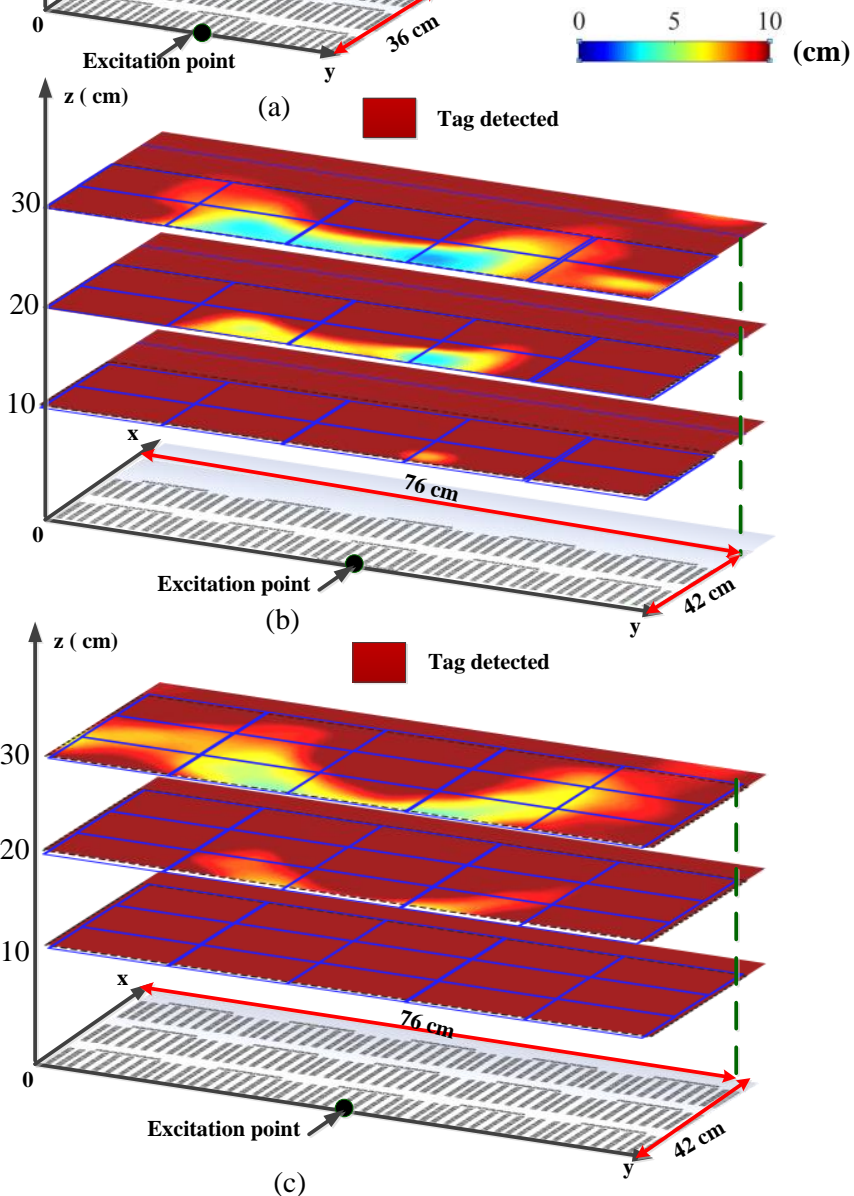

(c)

Fig. 20 Measurement results of the reading zone for different antenna configurations with a reader output power of $30 \mathrm{dBm}$, at $868 \mathrm{MHz}$, for $3 \mathrm{z}$ planes $(10,20$, and $30 \mathrm{~cm}$ ): (a) 9, (b) 10, (c) 15 blocks configuration. The color bar for each plane (10,20 and $30 \mathrm{~cm}$ ) is given in Fig. 20 (a).

In Fig. 21, we can see the measured reflection coefficient of two blocks with different excitation dipole lengths: one is designed to operate on a polyester support $\left(\varepsilon_{r}=1, l=18 \mathrm{~cm}\right)$, the second for a wooden table $\left(\varepsilon_{r}=2, l=15 \mathrm{~cm}\right)$. The same resonant frequency is obtained just by changing the dipole length.

In Table II, a comparison is drawn between the antenna introduced here and the already proposed designs in the literature. For the same tag size [24] and the same reader 
output level $(30 \mathrm{dBm})$, the proposed antenna has a significant reading range of about $35 \mathrm{~cm}$, which is much more important than the $3 \mathrm{~cm}$ obtained in [21] and the $7 \mathrm{~cm}$ of [11].

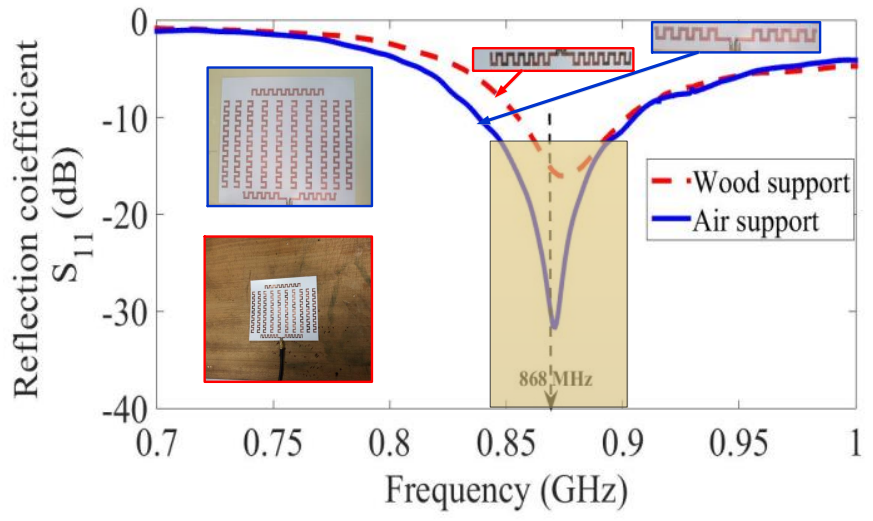

Fig. 21: Measured reflection coefficient for excitation block: continuous curve (air support), dotted curve (wood support).

Even standard UHF RFID tags $\left(9 \times 1 \mathrm{~cm}^{2}\right)$ are used like in [19], [22] , the reading range is still higher for the proposed antenna. When we consider the reading surface, the one of 76 $\times 42 \mathrm{~cm}^{2}$ obtained for the 15 blocks configurations at $15 \mathrm{~cm}$ is larger than the one obtained for the other designs even at a lower height.

TABLE II: COMPARISON BETWEEN DIFFERENT DESIGNS OF THE LITERATURE AND THE PROPOSED ANTENNA

\begin{tabular}{|c|c|c|c|c|}
\hline & $\begin{array}{l}\text { ANTENNA } \\
\text { TOPOLOGY }\end{array}$ & $\begin{array}{c}\text { TAG } \\
\text { (TAG } \\
\text { DIMENSIONS) }\end{array}$ & $\begin{array}{c}\text { READ } \\
\text { RANGE (CM) } \\
\underline{\text { /(INPUT }} \\
\underline{\text { POWER }} \\
\underline{(\text { DBM }))} \\
\end{array}$ & $\begin{array}{c}\text { READING } \\
\text { SURFACE (\% OF } \\
\text { THE ANTENNA } \\
\text { SURFACE) }\end{array}$ \\
\hline [19] & $\sum_{m=1}^{\infty}$ & $\begin{array}{c}\text { ALN-9540 } \\
\left(9.7 \times 1.1 \mathrm{~cm}^{2}\right)\end{array}$ & $5 /(30)$ & $\begin{array}{c}100 \times 30 \mathrm{~cm}^{2} \\
(100 \%)\end{array}$ \\
\hline [19] & $4=$ & $\begin{array}{c}\text { ALN-9540 } \\
\left(9.7 \times 1.1 \mathrm{~cm}^{2}\right)\end{array}$ & $15 /(30)$ & $\begin{array}{c}100 \times 30 \mathrm{~cm}^{2} \\
(100 \%)\end{array}$ \\
\hline [21] & 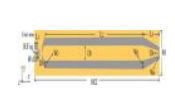 & $\begin{array}{l}\text { UPM Raflatac } \\
\text { Button }(1.1 \mathrm{~cm})\end{array}$ & $5 /(30)$ & $\begin{array}{c}88.2 \times 8 \mathrm{~cm}^{2} \\
(34 \%)\end{array}$ \\
\hline \multirow{2}{*}{ [22] } & & $\begin{array}{c}\text { UH113 } \\
\left(3.2 \times 1.8 \mathrm{~cm}^{2}\right)\end{array}$ & $10 /(23)$ & $\begin{array}{c}27.5 \times 13.5 \mathrm{~cm}^{2} \\
(60 \%)\end{array}$ \\
\hline & & $\begin{array}{c}\text { ALN } 9640 \\
\left(1.2 \times 10 \mathrm{~cm}^{2}\right)\end{array}$ & $50 /(23)$ & $\begin{array}{c}27.5 \times 13.5 \mathrm{~cm}^{2} \\
(70 \%)\end{array}$ \\
\hline \multirow[t]{2}{*}{ [24] } & 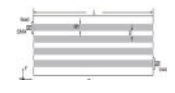 & $1.1 \times 1.1 \mathrm{~cm}^{2}$ & $3 /(30)$ & $\begin{array}{c}74.7 \times 17.6 \mathrm{~cm}^{2} \\
(90 \%)\end{array}$ \\
\hline & This Paper & $1.2 \times 1.1 \mathrm{~cm}^{2}$ & $35 /(30)$ & $\begin{array}{c}76 \times 42 \mathrm{~cm}^{2} \\
(70 \%)\end{array}$ \\
\hline
\end{tabular}

\section{CONCLUSION}

In this paper, a modular near-field antenna has been proposed for UHF RFID applications. The reading zone is totally configurable based on parasitic planar blocks that can be used to form the entire antenna topology to achieve the desired reading zone. Moreover, the antenna is produced with a very low cost technique, compatible with near-field UHF RFID applications. The antenna is entirely made of planar printed PET substrate realized with common large-scale manufacturing process. These planar blocks allow the antenna to be integrated at different supports. The proposed antenna can be configured to present a very large reading area of $76 \mathrm{~cm} \times 42 \mathrm{~cm}$ (15 blocks configuration), with a read range higher than $15 \mathrm{~cm}$ over the entire surface. Last but not the least, by reducing the number of blocks, the reading zone could be set to keep a read range of at least of $35 \mathrm{~cm}$ ( 9 blocks configuration), for an RFID reader output power of $27 \mathrm{dBm}$.

The antenna is modular and flexible. For example, block configurations where the driven module is placed at the center (and not on one edge as presented here) could potentially double the reading surface without any more modifications. Configurations with more than one driven block could also considerably enlarge the reading surface. Surface different from rectangle shape can also be obtained with the same approach.

\section{ACKNOWLEDGMENT}

The authors thank the RFT Lab, Christophe Medina, and Gianfranco Andia-Vera for their help in measurement.

\section{REFERENCES}

[1] L. Chunli and L. Donghui, "Application and development of RFID technique," in 2012 2nd International Conference on Consumer Electronics, Communications and Networks (CECNet), 2012, pp. 900903.

[2] Z. Min, L. Wenfeng, W. Zhongyun, L. Bin, and R. Xia, "A RFID-based Material Tracking Information System," in 2007 IEEE International Conference on Automation and Logistics, 2007, pp. 2922-2926.

[3] X. Li, T. Wang, J. Chen, J. Chen, Z. Qian, J. K. Pollard, S. Liu, and J. $\mathrm{Yu}$, "Customer service enhancement using passive RFID," in IEEE International Conference on Communications Technology and Applications, 2009. ICCTA '09, 2009, pp. 5-9.

[4] J. w Lee, H. Kwon, and B. Lee, "Design Consideration of UHF RFID Tag for Increased Reading Range," in 2006 IEEE MTT-S International Microwave Symposium Digest, 2006, pp. 1588-1591.

[5] J. w Lee and B. Lee, "Design of high-Q UHF radio-frequency identification tag antennas for an increased read range," Antennas Propag. IET Microw., vol. 2, no. 7, pp. 711-717, Oct. 2008.

[6] A. A. Babar, S. Manzari, L. Sydanheimo, A. Z. Elsherbeni, and L. Ukkonen, "Passive UHF RFID Tag for Heat Sensing Applications," IEEE Trans. Antennas Propag., vol. 60, no. 9, pp. 4056-4064, Sep. 2012.

[7] D. Yue, X. Wu, and J. Bai, "RFID Application Framework for pharmaceutical supply chain," in IEEE International Conference on Service Operations and Logistics, and Informatics, 2008. IEEE/SOLI 2008, 2008, vol. 1, pp. 1125-1130.

[8] D. Paret, RFID at ultra and super high frequencies: theory and application. John Wiley \& Sons, 2009.

[9] K. Finkenzeller, RFID Handbook: Radio-frequency identification fundamentals and applications. Wiley, 1999, page 22 and 46

[10] P. V. Nikitin, K. V. S. Rao, and S. Lazar, "An Overview of Near Field UHF RFID," in IEEE International Conference on RFID, 2007, 2007, pp. $167-174$. 
[11] X. Qing, C. K. Goh, and Z. N. Chen, "A Broadband UHF Near-Field RFID Antenna," IEEE Trans. Antennas Propag., vol. 58, no. 12, pp. 3829-3838, Dec. 2010.

[12] P. Yang, Y. Li, L.-J. Jiang, and F. Yang, "Near-Field Loop Antenna for the UHF RFID Reader," Journal of electronic science and technology, vol. 9, no. 3, 2011.

[13] X. Qing, C. K. Goh, and Z. N. Chen, "Segmented loop antenna for UHF near-field RFID applications," Electron. Lett., vol. 45, no. 17, pp. 872873, Aug. 2009.

[14] X. Qing, Z. N. Chen, and C. K. Goh, "UHF near-field RFID reader antenna with capacitive couplers," Electron. Lett., vol. 46, no. 24, pp. 1591-1592, 2010.

[15] J. Shi, X. Qing, Z. N. Chen, and C. K. Goh, "Electrically Large DualLoop Antenna for UHF Near-Field RFID Reader," IEEE Trans. Antennas Propag., vol. 61, no. 3, pp. 1019-1025, Mar. 2013.

[16] M. Daiki, E. Perret, and S. Tedjini, "Design of near field UHF RFID reader antenna integrated into clothing," in 2014 IEEE RFID Technology and Applications Conference (RFID-TA), 2014, pp. 261265.

[17] M. Daiki, E. Perret, and S. Tedjini, "Antenna Design for UHF RFID Near-Field Applications," Presented at the 7th Int. Conf. IEEE RFID, Orlando, USA, 2013.

[18] “CST - Computer Simulation Technology." [Online]. Available: https://www.cst.com/.

[19] C. R. Medeiros, J. R. Costa, and C. A. Fernandes, "RFID Reader Antennas for Tag Detection in Self-Confined Volumes at UHF," IEEE Antennas Propag. Mag., vol. 53, no. 2, pp. 39-50, Apr. 2011.

[20] W. Choi, J. s Kim, J. h Bae, G. Choi, and J. s Chae, "Near-field antenna for a radio frequency identification shelf in the uhf band," Antennas Propag. IET Microw., vol. 4, no. 10, pp. 1538-1542, Oct. 2010.

[21] A. Ren, C. Wu, Y. Gao, and Y. Yuan, "A Robust UHF Near-Field RFID Reader Antenna," IEEE Trans. Antennas Propag., vol. 60, no. 4, pp. 1690-1697, Apr. 2012.

[22] A. Michel, R. Caso, A. Buffi, P. Nepa, and G. Isola, "Meandered TWAS array for near-field UHF RFID applications," Electron. Lett., vol. 50, no. 1, pp. 17-18, Jan. 2014.

[23] “INLAYUHF-UH113."[Online].Available: http://www.identsys.se/website/index.php/produkter-aamp-webshopmainmenu26?page=shop.product_details \&product_id=317\&flypage=flypage.tpl \& pop $=0$.

[24] C. Y. Wu, J. Du, A. K. Ren, and J. Y. Li, "Large-area RFID reader antenna for smart shelf at UHF," Electron. Lett., vol. 48, no. 15, pp. 899-900, Jul. 2012.

[25] L.-C. Kuo, H.-R. Chuang, Y.-C. Kan, T.-C. Huang, and C.-H. Ko, “A study of planar printed dipole antennas for wireless communication applications," J. Electromagn. Waves Appl., vol. 21, no. 5, pp. 637-652, 2007.

[26] C. A. Balanis, Antenna theory: analysis and design. John Wiley \& Sons, 2016.

[27] "Blackroc Technology | Tagsys AK UHF tag (AK Tag)."

[28] J. Hong, J. Choo, J. Ryoo, and C. Choi, "A shelf antenna using nearfield without dead zones in UHF RFID," in IEEE International Conference on Industrial Technology, 2009. ICIT 2009, 2009, pp. 1-4.

[29] A. Vena, E. Perret, S. Tedjini, G. E. P. Tourtollet, A. Delattre, F. Garet, and Y. Boutant, "Design of chipless RFID tags printed on paper by flexography," Antennas Propag. IEEE Trans. On, vol. 61, no. 12, pp. 5868-5877, 2013.

[30] "inkJet FlexThe Centre for Process Innovation." [Online] Available: http://www.inkjetflex.com.

[31] "Impinj Speedway Revolution R420 UHF RFID Reader Evaluation Kit (4 Port)," atlasRFIDstore. [Online]. Available: http://www.atlasrfidstore.com/impinj-speedway-revolution-r420-uhfrfid-reader-evaluation-kit-4-port/. 